\title{
CD4 T cell-mediated cardiac allograft rejection requires donor but not host MHC class II
}

\author{
Biagio A. Pietra, ${ }^{1}$ Alex Wiseman, ${ }^{2}$ Amy Bolwerk, ${ }^{3}$ Mona Rizeq, ${ }^{4}$ and Ronald G. Gill ${ }^{3}$ \\ ${ }^{1}$ Division of Cardiology, The Children's Hospital, \\ ${ }^{2}$ Division of Nephrology, Department of Medicine, \\ ${ }^{3}$ Department of Medicine, Barbara Davis Center for Childhood Diabetes, and \\ ${ }^{4}$ Department of Pathology, Veterans Affairs Medical Center, University of Colorado Health Sciences Center, \\ Denver, Colorado, USA \\ Address correspondence to: Ronald G. Gill, Barbara Davis Center for Childhood Diabetes, \\ University of Colorado Health Sciences Center, 4200 East 9th Avenue, Box B-140, Denver 80262, USA. \\ Phone: (303) 315-6390; Fax: (303) 315-4124; E-mail: ron.g.gill@uchsc.edu.
}

Received for publication May 31, 2000, and accepted in revised form September 5, 2000.

Numerous studies indicate that CD4 T cells are required for acute cardiac allograft rejection. However, the precise role for $\mathrm{CD} 4 \mathrm{~T}$ cells in this response has remained ambiguous owing to the multipotential properties of this T-cell subpopulation. In the current study, we demonstrate the capacity of CD4 T cells to serve as direct effector cells of cardiac allograft rejection. We show that CD4 $T$ cells are both necessary and sufficient for acute graft rejection, as indicated by adoptive transfer experiments in immune-deficient SCID and rag $1^{-/-}$recipients. We have analyzed the contribution of direct (donor MHC class II restricted) and indirect (host MHC class II restricted) antigen recognition in CD4-mediated rejection. Acute CD4 $\mathrm{T}$ cell-mediated rejection required MHC class II expression by the allograft, indicating the importance of direct graft recognition. In contrast, reciprocal experiments indicate that CD4 $\mathrm{T}$ cells can acutely reject allogeneic cardiac allografts established in $\mathrm{rag}^{1 /-}$ hosts that were also MHC class II deficient. This latter result indicates that indirect presentation of donor antigens by host MHC class II is not required for acute CD4-mediated rejection. Taken together, these results indicate that $\mathrm{CD} 4 \mathrm{~T}$ cells can serve as effector cells for primary acute cardiac allograft rejection, predominantly via direct donor antigen recognition and independent of indirect reactivity.

J. Clin. Invest. 106:1003-1010 (2000).

\section{Introduction}

$\mathrm{CD} 4 \mathrm{~T}$ cells play a central role in the regulation of immune responses, including the initiation of allograft rejection. CD4 $\mathrm{T}$ cells are known to be necessary for cardiac allograft rejection, as illustrated by long-term allograft survival after anti-CD4 $\mathrm{mAb}$ therapy or grafting into CD4-deficient recipients (1-6). Although CD4 T cells often are required for allograft immunity, the precise role(s) of this subset remains ambiguous owing to the multifaceted role of CD4 T cells in cellular immune responses. For example, although CD4 T cells are generally regarded as helper cells by facilitating other lymphoid cells involved in immunity $(7-11)$, they have also been implicated as effector cells of graft rejection (12-14). Thus, the potential helper versus effector functions of CD4 $\mathrm{T}$ cells in graft rejection often remain unclear, as these activities occur simultaneously. One major goal of this study was to determine the capacity of CD4 T cells to mediate cardiac rejection in the absence of other lymphoid subpopulations.

Another complication in determining the role of $\mathrm{CD} 4 \mathrm{~T}$ cells in allograft rejection lies in the fact that these cells have two potential pathways of MHC class II-restricted donor antigen recognition: (a) "direct" recognition of allogeneic MHC class II molecules expressed by donor antigen presenting cells (APCs), and (b) "indirect" recognition of donor antigens processed and presented in the context of MHC class II molecules expressed by recipient APCs (15). CD4 T cells characteristic of both donor MHC-restricted direct (14) and host MHC-restricted indirect (8, 16-18) cells have been implicated in allograft immunity. In the present study, we determined whether CD4 $\mathrm{T}$ cells alone were sufficient to trigger the rejection of vascularized, heterotopic cardiac allografts in immune-deficient mice. Results show that CD4 T cells are both necessary and sufficient for mediating acute cardiac allograft rejection, and that this response requires donor but not host MHC class II expression, implicating direct donor recognition in this response.

\section{Methods}

Mice. Inbred female C57BL/6ByJ (B6, H-2 b), BALB/cByJ $\left(\mathrm{BALB} / \mathrm{c}, \mathrm{H}-\mathrm{2}^{\mathrm{d}}\right.$ ) mice, and C57BL/6-Rag1 ${ }^{\text {tm1/Mom }}$ (B6 rag1 $\left.1^{--}, \mathrm{H}-2^{\mathrm{b}}\right)$ were purchased from The Jackson Laboratory (Bar Harbor, Maine, USA). Female C57BL/6 I-A $\mathrm{A}_{-}$ gene targeted $\mathrm{MHC}$ class $\mathrm{II}^{-/-}$deficient $\left(\mathrm{C} 2 \mathrm{D}, \mathrm{H}-2^{\mathrm{b}}\right)$ mice (19) and immune-deficient C.B-17scid/scid (SCID, $\mathrm{H}-2^{\mathrm{d}}$ ) female mice (20) were obtained from Taconic Farms (Germantown, New York, USA). Animals were 
housed under pathogen-free conditions at the University of Colorado Barbara Davis Center Animal Facility, according to NIH guidelines.

Generation of $C 2 D$ rag $1^{-/}$mice. To generate immunedeficient rag $1^{-/-}$mice that were also MHC class II deficient, C2D mice were crossed with $\mathrm{B} 6 \mathrm{rag} 1^{-/-}$mice and then intercrossed to generate double-deficient mice. The rag $1^{-/}$phenotype was determined by the lack of detectable lymphocytes in peripheral blood leukocytes (PBLs), and the C2D genotype was assessed by PCR screening of genomic DNA for the disrupted $\mathrm{IA}_{\beta}{ }^{\mathrm{b}}$ allele. The C2D phenotype also was confirmed functionally by the inability of C2D stimulator cells to trigger in vitro proliferation of BALB/c CD4 T cells relative to $\mathrm{MHC}$ class $\mathrm{II}^{+/+}$rag $1^{-/-}$stimulator cells. Homozygous C2D rag $1^{-/-}$mice then were interbred for experimental use.

Heterotopic heart transplantation. Cardiac allografts from $\mathrm{BALB} / \mathrm{c}$ mice were transplanted heterotopically into B6,

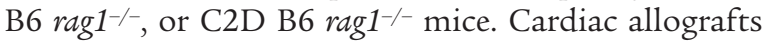
from $\mathrm{B} 6$ or $\mathrm{C} 2 \mathrm{D}$ mice were transplanted heterotopically into BALB/c mice or into SCID mice. Vascularized grafts were transplanted according to standard microsurgical techniques (21). Briefly, the harvested donor heart was placed in $4^{\circ} \mathrm{C}$ saline until transplantation. Under avertin-induced anesthesia, a $2-\mathrm{cm}$ midline vertical abdominal incision was made, and the abdominal cavity entered. The abdominal aorta and inferior vena cava (IVC) were isolated below the renal vessels. An end to side anastomosis of the donor aorta to the recipient aorta was made using running 10-0 nylon suture. An end to side anastomosis of the donor pulmonary artery to the recipient IVC was made in similar fashion. The abdominal wall was closed in two layers using 5-0 silk suture in a running fashion. A 1.0-ml bolus of sterile normal saline was administered into the abdomen as fluid resuscitation upon closing. No other supportive measures were required during the surgery. Heart graft survival was monitored by daily palpation with rejection defined as cessation of detectable beat.

CD4 T-cell depletion in vivo. The rat anti-mouse CD4 mAb GK 1.5 (IgG2b) (22) was produced for in vivo CD4 T-cell depletion. GK1.5 antibody was generated as ascites in SCID mice and quantitated by an isotype-specific ELISA. BALB/c recipients were either left untreated or were treated with GK1.5 antibody $(10 \mathrm{mg} / \mathrm{kg})$ administered intraperitoneally to the indicated BALB $/ \mathrm{c}$ recipients on days $-1,0,1$, and 2 relative to transplant.

CD4 T-cell purification and adoptive transfer. Cervical, axillary, and mesenteric lymph nodes (LNs) were harvested from BALB/c or B6 mice. Single-cell suspensions of $\mathrm{LN}$ cells were enriched for CD4 T cells by negative selection of CD8 $\mathrm{T}$ cells and $\mathrm{B}$ cells on an immunoaffinity column according to the manufacturer's specifications (Cellect, Edmonton, Alberta, Canada). Where indicated, B6 CD4-enriched lymphoid populations were further depleted of residual MHC class II-bearing cells with anti-I-A ${ }^{\mathrm{b}}$ antibody (25-9-3S; IgM) plus rabbit complement (LowTox-M; Accurate Chemi- cal \& Scientific Corp., Westbury, New York, USA) treatment for 1 hour at $37^{\circ} \mathrm{C}$. Cellular phenotyping of freshly purified cells or of PBLs of adoptive transfer recipients was determined by flow cytometry assessing staining of FITC-labeled anti-CD4, anti-CD8, or antiB220 mAb's (PharMingen, San Diego, California, USA) detected by an EPICS ELITE ESP flow cytometer (Coulter Corp., Miami, Florida, USA). CD4-enriched T cells contained less than $0.5 \%$ contaminating CD8 T cells or B220+ cells. Ten million unseparated LNs or CD4enriched $\mathrm{T}$ cells were injected intraperitoneally into the indicated adoptive transfer recipients on day 0 relative to cardiac transplant.

Mixed lymphocyte reaction of reconstituting lymphoid populations. Mixed lymphocyte reaction (MLR) of adoptively transferred cell populations were also performed to demonstrate cell viability and function. Briefly, $2.0 \times 10^{5}$ responder cells were mixed with $3.0 \times 10^{5}$ irradiated (3000R) splenic stimulator cells in 96-well flat-bottom plates. Cells, cultured in EMEM supplemented with $10 \% \mathrm{FCS}, 10^{-5} \mathrm{M} 2-\mathrm{Me}$, and antibiotics, were incubated at $37^{\circ} \mathrm{C}$ in $10 \% \mathrm{CO}_{2}$. Cultures then were pulsed with 1.0 $\mu \mathrm{Ci}\left[\mathrm{H}^{3}\right]$ thymidine for 6 hours on the indicated day of cell culture. Plates were harvested and counted on a TopCount microplate scintillation counter (Packard Instrument Corp., Meriden, Connecticut, USA).

Tissue histological examination. Transplanted and native hearts were removed and divided in half in long axis perpendicular to the intraventricular septum. One half of the transplant was fixed in $10 \%$ formalin, and the other was imbedded in OTC and snap frozen to $-70^{\circ} \mathrm{C}$. The formalin fixed tissue was paraffin embedded, and sections were cut and stained with hematoxylin and eosin $(\mathrm{H} \& \mathrm{E})$ and trichrome stains. These were examined in a blinded fashion to determine the extent of myocardial damage, mononuclear and granulocyte cell infiltration, and vasculitis and/or vascular intimal proliferation.

Parallel sections were analyzed by immunohistochemistry on frozen tissue sections by air drying overnight and fixing with acetone. Sections were rehydrated in TBS, washed, and then blocked with 1:5 normal rabbit serum in TBS containing Vector avidin $\mathrm{DH}$ (Vector Laboratories Inc., Burlingame, California, USA). KT6 supernatant (rat anti-mouse CD4) or YTS105 supernatant (rat anti-mouse CD8) was applied and incubated for 45 minutes at room temperature. Biotinylated rabbit anti-rat Ig (1:200) was applied and incubated for 30 minutes. Vectastain Elite ABC Reagent (Vector Laboratories Inc.) was applied and then counter stained with Mayer's hematoxylin. Tissue sections were examined for immunoperoxidase staining by light microscopy for the presence of CD4 and/or CD8 T cells.

Detection of alloantibody production. Alloreactive antibody production was assessed by the ability of sera from grafted animals to fix complement to ${ }^{51} \mathrm{Cr}$-labeled Con A blast target cells. Briefly, $10^{4}$ labeled blast target cells were mixed with serial twofold dilutions of test sera and rabbit complement (LowTox-M) in $200 \mu \mathrm{l}$ and 
Table 1

FACS analysis of lymphocyte populations used for adoptive transfer to SCID recipients

\begin{tabular}{|c|c|c|c|c|c|c|}
\hline Cell population ${ }^{\mathrm{A}}$ & Recipient & $\begin{array}{l}\text { Day of analysis } \\
\text { (days after transfer) }\end{array}$ & $\begin{array}{l}\text { TCR } \\
(\%)\end{array}$ & $\begin{array}{l}\text { CD4 } \\
(\%)\end{array}$ & $\begin{array}{l}\text { CD8 } \\
(\%)\end{array}$ & $\begin{array}{c}\text { B220 } \\
(\%)\end{array}$ \\
\hline \multicolumn{7}{|l|}{ Before transfer ${ }^{B}$} \\
\hline $\begin{array}{l}\text { Unseparated LN } \\
\text { Purified CD4 }\end{array}$ & $\begin{array}{l}- \\
-\end{array}$ & $\begin{array}{l}0 \\
0\end{array}$ & $\begin{array}{l}56.5 \\
97.3\end{array}$ & $\begin{array}{l}46.5 \\
97.1\end{array}$ & $\begin{array}{c}12.1 \\
0.0\end{array}$ & $\begin{array}{c}36.8 \\
0.1\end{array}$ \\
\hline \multicolumn{7}{|c|}{ PBL of adoptive transfer recipient } \\
\hline $\begin{array}{l}\text { Unseparated LN } \\
\text { Purified CD4 } \\
\text { None } \\
\text { None }\end{array}$ & $\begin{array}{l}\text { SCID } \\
\text { SCID } \\
\text { BALB/c } \\
\text { SCID }\end{array}$ & $\begin{array}{l}14 \\
14 \\
14 \\
60\end{array}$ & $\begin{array}{c}38.8 \\
26.8 \\
63.3 \\
2.7\end{array}$ & $\begin{array}{c}25.0 \\
24.7 \\
48.8 \\
0.1\end{array}$ & $\begin{array}{c}11.3 \\
0.2 \\
14.1 \\
0.2\end{array}$ & $\begin{array}{c}1.3 \\
0.5 \\
25.1 \\
0.2\end{array}$ \\
\hline
\end{tabular}

${ }^{A}$ A total of $1 \times 10^{7}$ unseparated LN cells or purified CD4 T cells were adoptively transferred to SCID mice grafted with cardiac allografts. Cells used for adoptive transfer were phenotyped by FACS analysis on the day of cell transfer or were analyzed in PBLs of adoptive transfer recipients on the day indicated. For

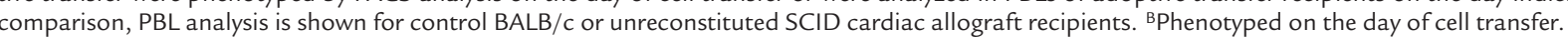

incubated in 96-well V-bottom tissue culture plates for 1 hour at $37^{\circ} \mathrm{C}$. The ${ }^{51} \mathrm{Cr}$ release was measured on a microplate scintillation counter, and end-point titers were determined as the reciprocal of the serum dilution producing ${ }^{51} \mathrm{Cr}$-release greater than $3 \mathrm{SD}$ above replicate wells of target cells plus complement alone.

Statistical analysis. Mann-Whitney $U$ and Fischer exact tests using commercially available software were used to determine significance of graft survival data in adoptive transfer studies.

\section{Results and Discussion}

CD4 T cells are both necessary and sufficient for acute cardiac allograft rejection in immune-deficient recipients. Previous studies indicate that $\mathrm{CD} 4+\mathrm{T}$ cells are necessary for cardiac allograft immunity $(6,23-27)$. Consistent with these studies, the depletion of recipient CD4 T cells with a short course of $\mathrm{mAb}$ therapy (GK1.5) prevented acute rejection of B 6 cardiac allografts with 4/4 grafts functioning for greater than 60 days (Figure 1a). The role of CD4 $\mathrm{T}$ cells in rejection was further analyzed in an adoptive transfer model using immunedeficient SCID recipients. Donor B6 $\left(\mathrm{H}-2^{\mathrm{b}}\right)$ cardiac allografts survived greater than 60 days in unreconstituted SCID mice (Figure 1b), in contrast to the acute rejection of these grafts in immune-competent $\mathrm{BALB} / \mathrm{c}$ recipients. At harvest (> 60 days), such heart allografts established in SCID mice lacked any overt histological evidence of acute rejection or graft vascu- lopathy (Figure 2). Furthermore, such SCID hosts failed to demonstrate peripheral endogenous, or "leaky," host-derived lymphocytes over the course of the experiment (Table 1). Initial studies were performed to determine the number of wild-type BALB/c lymph node cells required to transfer robust cardiac allograft rejection to immune-deficient SCID recipients. On the basis of our previous studies of islet allograft rejection (28) and cardiac allograft rejection, either $3 \times 10^{7}(n=5)$ or $1 \times 10^{7}(n=7) \mathrm{BALB} / \mathrm{c}$ lymph node cells were transferred to SCID mice bearing B6 heart allografts, with acute rejection triggered in a mean of $9.6 \pm 1.8$ and $12.4 \pm 1.7$ days, respectively $(P=$ NS). Because these two dosage groups did not show significant differences in rejection rates, $1 \times 10^{7}$ cells were used for adoptive transfer in subsequent studies, to minimize the risk of transferring contaminating lymphocytes (CD8 T cells or B cells) in experiments involving purified CD4 T cells. Importantly, LN cells depleted of CD4 $\mathrm{T}$ cells were unable to reconstitute cardiac allograft rejection to SCID hosts (Figure 1b). Thus, CD4 T cells were required for acute cardiac allograft rejection in either wild-type recipients or in recipients with adoptively transferred cellular immunity.

To determine whether CD4 T cells were actually sufficient for triggering acute cardiac allograft rejection, allograft-bearing SCID mice were reconstituted with purified BALB/c CD4 T cells. Such CD4 T cells acutely rejected cardiac grafts in a time course comparable to

\section{Figure 1}

CD4 T cells are necessary for cardiac allograft rejection. (a) C57BL/6 cardiac allografts are rejected in immune competent BALB/c recipient $(n=10$, mean $=8.3 \pm 1.6$ days $)$, whereas mice treated with 10 $\mathrm{mg} / \mathrm{kg}$ of anti-CD4 antibody (GK-1.5) do not reject C57BL/ 6 hearts $(n=4 ;>60$ days $\times 4)$. (b) C57BL/ 6 cardiac allografts are not rejected in unreconstituted C.B-17scid (SCID) mice $(n=12 ;>60$ days $\times$ 12). C57BL/ 6 cardiac allografts are rejected in SCID mice reconstituted with LN cells from immune competent BALB/c mice $(n=7$; mean $=12.4 \pm 4.5$ days), whereas BALB/c cell donors treated with $10 \mathrm{mg} / \mathrm{kg}$ of anti-CD4 antibody (GK-1.5) before transfer do not reject C57BL/ 6 hearts $(n=4 ;>60$ days $\times 4)$.

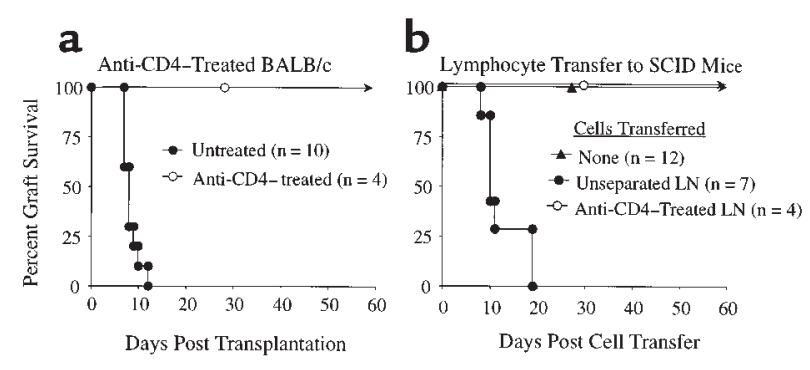


either control immune-competent BALB/c animals or SCID mice receiving unseparated whole LN cells (Figure 3a). Therefore, adoptive transfer of CD4+ T cells alone is sufficient to restore primary acute rejection of cardiac allografts in SCID mice. Several criteria of cellular phenotyping were used to verify that the transferred CD4 T cell populations were indeed devoid of demonstrable contaminating CD8 T cells or B cells. In animals reconstituted with $\mathrm{CD} 4 \mathrm{~T}$ cells, the enriched CD4 T-cell population contained less than $0.5 \%$ CD8 T cells or B cells as detected by FACS analysis of the adoptively transferred cells both prior to cell transfer and at the conclusion of the experiment through the analysis of the PBLs of SCID recipients (Table 1). In addition, immunohistochemical analysis of tissue sections of cardiac allografts rejected by purified CD4 $\mathrm{T}$ showed pronounced infiltration of $\mathrm{CD} 4 \mathrm{~T}$ cells without detectable contaminating CD8 or B cells (Figure 2). Finally, recipients of cardiac allografts were tested for the presence of complement-fixing antibodies reactive against donor-type target cells. Results indicated that although wild-type BALB/c mice and a proportion of SCID recipients of whole $\mathrm{LN}$ cells produced robust antibody responses, SCID recipients of purified CD4 T

\footnotetext{
Figure 2

Histological assessment of cardiac allografts. (a) Rejection of B6 cardiac allografts in untreated wild-type BALB/c recipients. (b) Rejection of C2D cardiac allografts in untreated wild-type BALB/C recipients. Grafts ( $\mathbf{a}$ and $\mathbf{b}$ ) demonstrate interstitial lymphocytic infiltrate, cardiac myocyte necrosis, and vasculitis consistent with acute rejection. (c) $\mathrm{C} 57 \mathrm{BL} / 6$ donor heart harvested from SCID at greater than 60 days, demonstrating normal cardiac myocytes and vasculature without evidence of rejection. (d) C57BL/ 6 donor heart rejected in SCID mice reconstituted with LN cells, demonstrating acute rejection with mild lymphocytic infiltrate, cardiac myocyte necrosis. (e) C57BL/6 donor heart rejected in SCID reconstituted with purified CD4 T cells. Moderate lymphocytic infiltrate and myocyte necrosis. (f) CD4 immunohistochemical staining in C57BL/ 6 donor hearts rejected in SCID mice reconstituted with CD4 T cells (day 14 after cell transfer). (g) Immunohistochemical staining in C57BL/ 6 donor hearts rejected in SCID mice reconstituted with CD4 T cells (same animal as depicted in f). Note the lack of detectable CD8-positive staining. (h) C2D C57BL/ 6 cardiac allograft from a CD4 T-cell reconstituted SCID mouse 60 days after CD4 T-cell transfer. Mild acute rejection with vasculitis, with pronounced intimal proliferation, is seen within the vessel wall consistent with the lesion of transplant coronary disease. All photomicrographs, $\times 165$
}

cell did not generate detectable donor-reactive antibodies (Figure 4). Taken together, we conclude that CD4 T cells are both necessary and sufficient to trigger primary acute cardiac allograft rejection in the absence of either CD8 T cells or B cells. Although these lymphoid subsets may certainly contribute to graft rejection, neither CD8 $\mathrm{T}$ cells nor B cells are required for acute rejection, consistent with results in other heart allograft studies $(6,29)$. In contrast, other tissues, such as pancreatic islet rejection, can require CD8 T cells for acute rejection $(28,30)$.

CD4 T-mediated rejection requires donor MHC class II expression. A key issue regarding CD4-mediated rejection was whether the rejection occurred via direct MHC class II presentation by the graft and/or via indirect donor antigen presentation by host MHC class II-bearing APCs (15). To determine whether direct presentation of donor MHC class II is essential for acute CD4-mediated rejection, SCID mice were grafted with C2D heart allografts such that the host, but not the donor, expressed MHC class II. Results indicate that most C2D heart allografts survived more than 60 days after CD4 T-cell transfer (Figure 3b), in sharp contrast to the acute rejection of MHC class II-bearing allografts (Figure 3a).
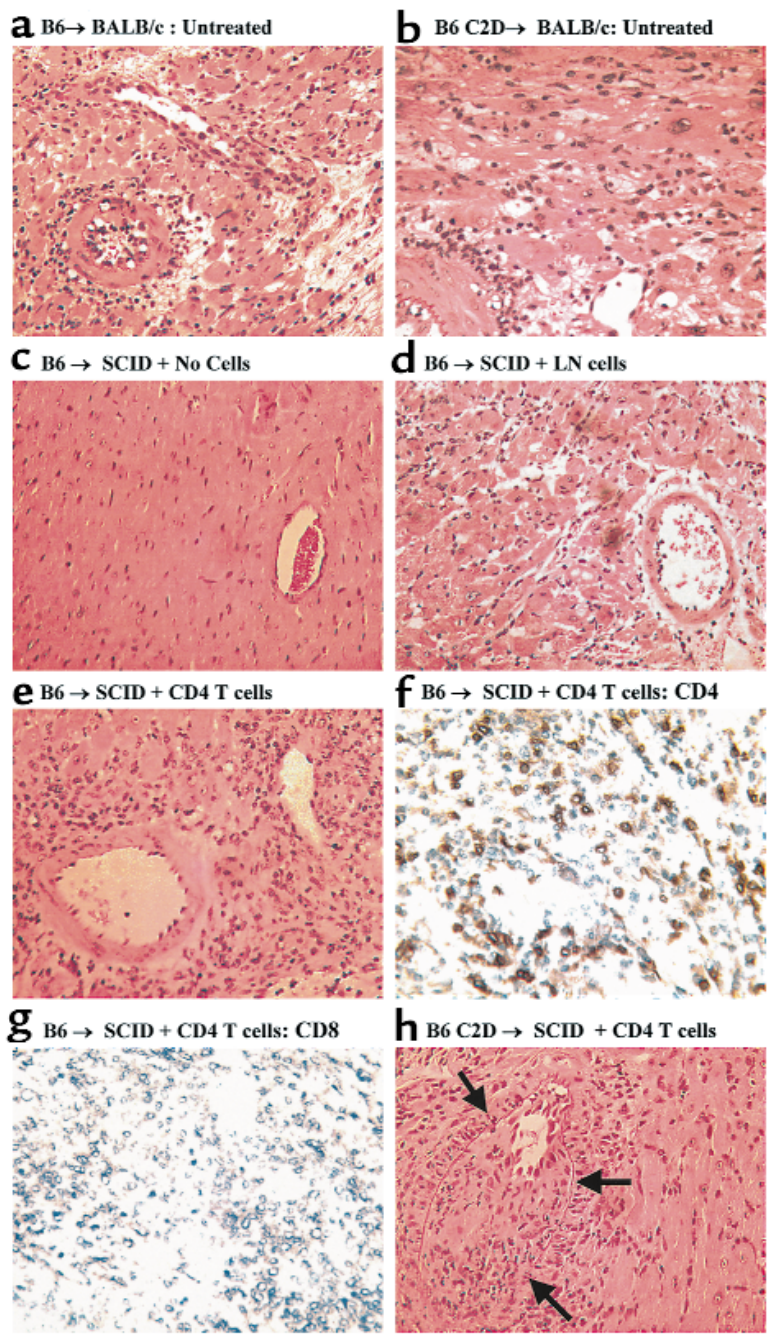


\section{Figure 3}

CD4 T cells are sufficient for acute rejection of $\mathrm{MHC}$ class $\mathrm{II}^{+/+}$but not C2D cardiac allografts. (a) C57BL/ 6 cardiac allografts survive greater than 60 days in SCID recipients (open triangles). Mice reconstituted with either unseparated LN cells (filled circles; $n=7$ ) or purified CD4 T cells (open circles; $n=10$ ) reject C57BL/ 6 hearts acutely (mean rejection of $12.4 \pm 4.5$ and $12 \pm 4.7$ days, respectively). (b) C2D C57BL/ 6 cardiac allografts survive more than 60 days in SCID recipients (open triangles). Mice reconstituted with unseparated LN cells (filled circles; $n=6$ ) acutely reject C2D C57BL/ 6 cardiac allografts in $9.8 \pm 0.3$ days, whereas purified CD4 T cells (open circles; $n=8$ ) do not reject the majority of C2D C57BL/ 6 hearts (graft survival of $50 ;>60 \times 7$ days).

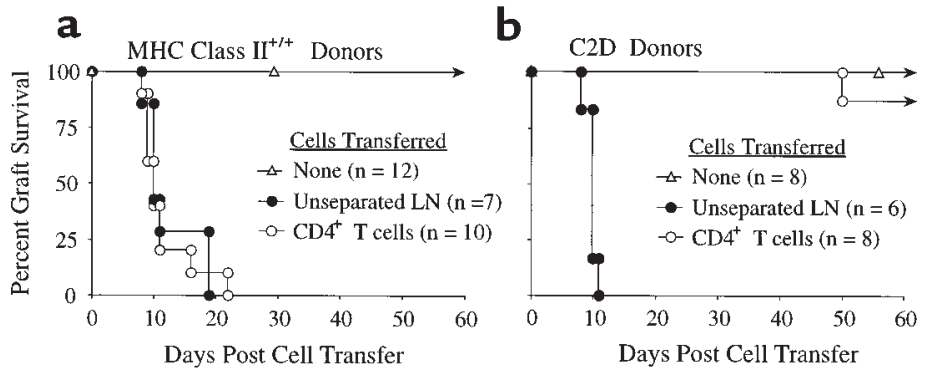

recipients (data not shown), indicating that donor MHC class II is not required for the generation of robust anti-donor antibody responses. Second, CD4 $T$ cells can contribute to cardiac allograft rejection in the absence of donor MHC class II expression. C2D hearts are in fact acutely rejected in SCID hosts by unseparated LN cells with kinetics equal to B6 MHC class $\mathrm{II}^{+/+}$hearts (Figure 3). Importantly, parallel experiments in wild-type BALB/c mice show that the rejection of $\mathrm{C} 2 \mathrm{D}$ heart allografts is $\mathrm{CD} 4 \mathrm{~T}$ cell dependent, despite the absence of direct CD4 reactivity (Figure 3). That is, although BALB/c hosts acutely reject $\mathrm{C} 2 \mathrm{D}$ hearts, anti-CD $4 \mathrm{mAb}$ therapy prevents this response (Figure 6). Thus, indirect CD4 T-cell reactivity can play an important role in recognizing the C2D graft. This result itself illustrates the fact that CD4 T cells have alternate means of contributing to cardiac allograft rejection, serving as direct effector cells when donor class II is present, or serving as

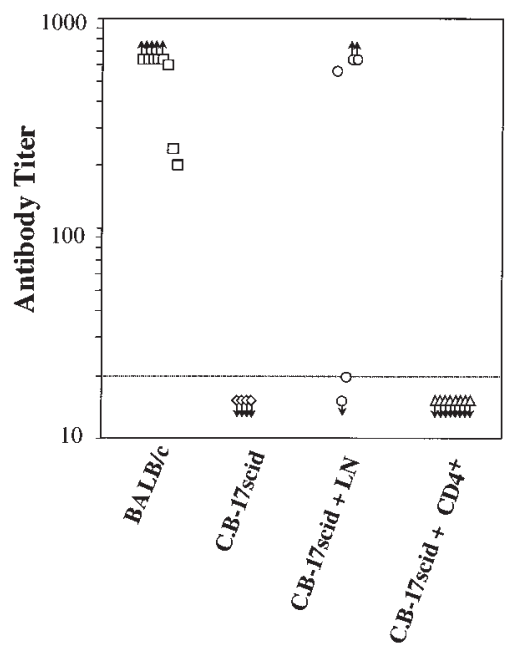

\section{Figure 4}

Alloantibody production from cardiac allograft recipients. Anti-B6 complement-fixing antibody titers were determined in the following experimental groups: wild-type BALB/c hosts grafted with B6 heart allografts (squares); nongrafted control SCID mice (diamonds); $\mathrm{SCID}$ mice grafted with $\mathrm{B} 6$ hearts and reconstituted with $10^{7} \mathrm{BALB} / \mathrm{C}$ whole LN cells (circles); and SCID mice grafted with B6 hearts and reconstituted with $10^{7}$ purified BALB/c CD4 T cells (triangles). 


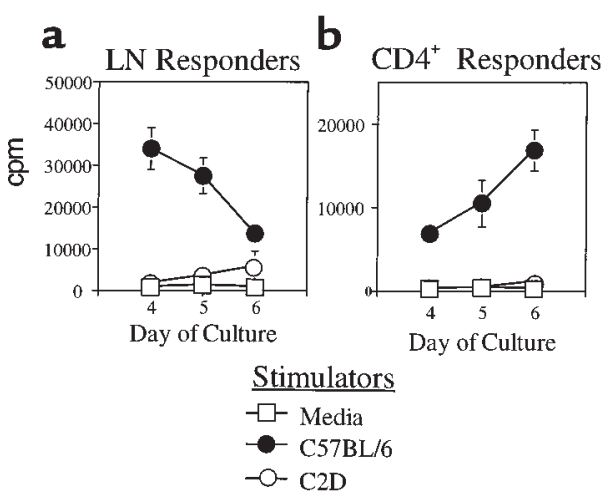

Figure 5

MLR of purified CD4+ lymphocytes. Proliferative response of (a) unseparated $\mathrm{LN}$ cells or $(\mathbf{b})$ purified CD4 T cells to either MHC class $\mathrm{II}^{+}(\mathrm{C} 57 \mathrm{BL} / 6)$ or $\mathrm{MHC}$ class $\mathrm{II}^{-/-}(\mathrm{C} 2 \mathrm{D})$ stimulator cells in vitro.

helper cells for graft rejection when the transplant is devoid of MHC class II. We are currently pursuing the nature of this CD4 $\mathrm{T}$ cell collaboration with other lymphoid subpopulations in the rejection of $\mathrm{C} 2 \mathrm{D}$ heart allografts. Finally, CD4 T cells do not require recipient MHC class II expression to acutely reject cardiac allografts (see below). Therefore, although indirect reactivity to donor MHC class II occurs, such a response is not necessary for acute rejection.

In the absence of donor MHC class II antigens, CD4+ T cells appear to mediate transplant coronary vasculopathy. Although C2D cardiac allografts are not rejected acutely in SCID mice reconstituted with only CD4 T cells, these hearts did show clear evidence of vascular changes at the time of graft harvest (60 days). Histological evidence of intimal proliferation in the coronary and aortic vasculature consistent with transplant coronary vasculopathy was seen in these grafts (Figure $2 \mathrm{~h}$ ). Hearts that survived long term in SCID mice that were not reconstituted with lymphoid cells did not have detectable coronary vasculopathy even after longer engraftment periods (>100 days). This finding indicates that despite the inability of CD4 $\mathrm{T}$ cells to generate direct donor reactivity to $\mathrm{C} 2 \mathrm{D}$ grafts, the presentation of donor antigens by recipient MHC class II can result in graft vascular pathology. This important secondary observation indicates that: (a) the indirect pathway is not sufficient to trigger acute, CD4-mediated rejection, and (b) transplant coronary vasculopathy can be triggered by CD4 $\mathrm{T}$ cells in the absence of donor MHC class II and host CD8 T-cell or B-cell responses. We are currently pursuing the nature of the chronic vascular changes seen in this model system.

CD4 $T$ cells trigger acute cardiac allograft rejection in the absence of the indirect pathway. As discussed earlier, donor MHC class II expression by the graft was necessary for acute CD4 T cell-mediated cardiac allograft rejection. This finding implicates the predominance of the direct pathway of donor recognition in this response and suggests that indirect antigen recognition by $\mathrm{CD} 4 \mathrm{~T}$ cells is insufficient for mediat- ing acute rejection. However, these results do not preclude a potentially significant role for indirect recognition in the activation or expression of CD4-mediated immunity. For example, primary indirect CD4 reactivity could conceivably be required to facilitate direct CD4 reactivity in vivo. To determine whether CD4-dependent indirect recognition was required for rejection, we performed reciprocal experiments to those described earlier, i.e., whether MHC class II-bearing cardiac allografts could be rejected by CD 4 $\mathrm{T}$ cells in the absence of host MHC class II expression. To accomplish this, C2D animals were bred with immune-deficient $\mathrm{B} 6 \mathrm{rag} 1^{-/}$mice to generate $\mathrm{C} 2 \mathrm{D} / \mathrm{rag} 1$ double-deficient recipients. BALB/c cardiac allografts were transplanted into either MHC class $\mathrm{II}^{+}$rag $1^{-/-}$or $\mathrm{C} 2 \mathrm{D}$ rag $1^{-/-}$recipients that subsequently were reconstituted with purified, MHC class II-depleted CD4 T cells. Results indicate that CD4 T cells can in fact trigger acute cardiac allograft rejection in the absence of host MHC class II (Figure 7). Thus, indirect donor antigen presentation by host MHC class II is not required for acute CD4-mediated cardiac allograft rejection. In contrast, using this same model system we have recently found that CD4 T cells do require host MHC class II for the rejection of rat islet xenografts (R.G. Gill et al., work in preparation), a result consistent with other studies of skin xenograft rejection (37). Thus, other forms of CD4mediated rejection do indeed require antigen recognition in association with host MHC class II.

This latter result may be considered somewhat surprising for at least two different reasons. First, previous studies have indicated that recent CD4+ thymic emigrants persist poorly in an MHC class II-deficient environment, presumably due to a requirement for tonic CD4/MHC class II interactions in the periphery $(38,39)$. Thus, there is some question whether CD4 T cells can function under extrathymic MHC class $\mathrm{II}^{-/-}$ conditions. In the current studies using peripheral,

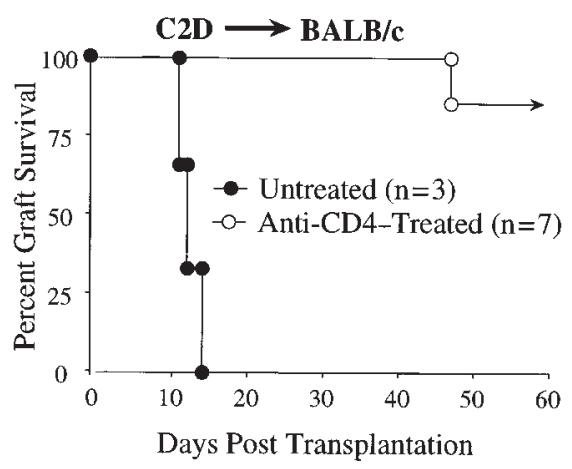

\section{Figure 6}

CD4 T cells are necessary for acute rejection of C2D cardiac allografts. BALB/c recipients of C2D heart allografts were either untreated (filled circles; $n=3$ ) or were depleted of CD4 T cells (open circles; $n=7$ ) through a short-course of anti-CD4 mAb therapy (GK1.5) as described in Methods. 


\section{Figure 7}

CD4 T cell-mediated rejection of cardiac allografts in immune-deficient rag $1^{-/-}$recipients. (a) MHC class $\mathrm{II}^{+} \mathrm{C} 57 \mathrm{BL} / 6$ rag $1^{-/-}$recipients were grafted with $B A L B / c$ heart allografts and reconstituted with either unseparated B6 LN cells or with purified CD4T cells. (b) MHC class II-deficient C2D C57BL/6 rag 1-/- recipients were grafted with $\mathrm{BALB} / \mathrm{c}$ heart allografts and reconstituted with B6 CD4 T cells that were further depleted of MHC class II-positive cells.

mature CD4 cells derived from wild-type mice, we have not noted this pronounced diminution in peripheral CD4 T cells after adoptive transfer to C2D hosts. A recent study, however, shows that mature $\mathrm{CD} 4^{\text {hi }} \mathrm{T}$ cells depleted of $\mathrm{CD} 8^{\text {lo }}$ double-positive $\mathrm{T}$ cells can persist for at least several months in C2D hosts (40), a result consistent with our own study. Furthermore, in the present study, the recipient does contain MHC class II expressed by the donor transplant, which makes the current model distinct from previous studies of CD4 T cells in C2D hosts. That is, it is possible that the donor MHC class II facilitates CD4 $\mathrm{T}$-cell function in the absence of endogenous MHC class II. A second point is that other studies suggest that host expression of costimulatory molecules, especially host CD80/86, play a greater role in cardiac allograft rejection than do donor costimulatory molecules (41). Such results highlight the importance of costimulation by host APCs in rejection, possibly through indirect antigen recognition. It is not clear how our results and these previous studies using CD80/86-deficient mice can be reconciled. However, the function of $\mathrm{CD} 4 \mathrm{~T}$ cells that develop in a CD80/86-deficient environment may differ from wild-type CD4 T cells used in our study. This important issue remains to be resolved.

In summary, these data demonstrate that CD4 T cells are both necessary and sufficient to trigger acute cardiac allograft rejection. Thus, CD4 $\mathrm{T}$ cells can function as effector cells in cardiac allograft immunity in the absence of other lymphocyte subpopulations. This does not exclude or minimize the contribution of other cells (CD8 or B cells) to acute rejection, but indicates that these cells are not required for the acute response. Importantly, CD4mediated rejection appears to primarily depend on direct donor recognition of MHC class II and occurs without a requirement for indirect presentation of donor antigens by host MHC class II molecules. The effector mechanism(s) of CD4-mediated heart allograft rejection remains unclear. In a skin allograft model, CD4 T cells could mediate rejection without a requirement for perforin, FasL (CD95L), or TNF, suggesting that prototypical cytotoxic $\mathrm{T}$ lymphocyte mechanisms were not required for graft rejection (42). We are currently investigating whether CD4-mediated cardiac allograft rejection shows similar properties.
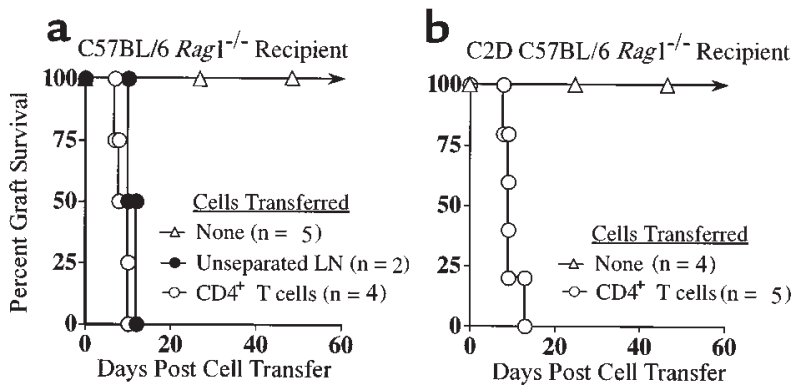

Also, it is not clear what type of donor MHC class II interaction is critical for CD4 $\mathrm{T}$ cell-mediated rejection. Bone marrow chimera experiments should aid in determining whether tissue parenchymal and/or vascular cell versus hematapoietic cell MHC class II expression is required for acute rejection. Although these important issues remain to be resolved, it is clear that CD4 T cells function as formidable effector cells capable of mediating primary acute rejection. The ambiguity regarding the contribution of CD4 $\mathrm{T}$ cells to acute rejection may lie in the fact that both helper and effector properties of CD4 $\mathrm{T}$ cells occur simultaneously during unmodified graft rejection.

\section{Acknowledgments}

This work was supported by grants from the NIH (KO8 5-KO8HL03594-03 and RO1 DK33470). The authors thank Philip Pratt for help in the preparation of figures for the manuscript, and Brian Kelly and Duane Walborn for technical assistance.

1. Shizuru, J.A., et al. 1990. Induction of donor specific unresponsiveness to cardiac allografts in rats by pretransplant anti-CD4 monoclonal antibody therapy. Transplantation. 50:366-371.

2. Onodera, K., et al. 1996. Induction of "infectious" tolerance to MHCincompatible cardiac allografts in CD4 monoclonal antibody-treated sensitized rat recipients. J. Immunol. 157:1944-1950.

3. Pearson, T.C., Hamano, K., Morris, P.J., and Wood, K.J. 1993. Anti-CD4 monoclonal antibody-induced allograft survival is associated with a defect in interleukin-2-dependent T-cell activation. Transplant. Proc. 25:786-787.

4. Pearson, T.C., Darby, C.R., and Wood, K.J. 1992. Successful secondary heterotopic cardiac transplantation in the mouse. Transplantation. 53:701-703.

5. Orosz, C.G., et al. 1996. Prevention of murine cardiac allograft rejection and gallium nitrate. Comparison with anti-CD4 monoclonal antibody. Transplantation. 61:783-791.

6. Krieger, N.R., Yin, D.P., and Fathman, C.G. 1996. CD4+ but not CD8+ cells are essential for allorejection. J. Exp. Med. 184:2013-2018.

7. Gill, R.G. 1993. T-cell-T-cell collaboration in allograft responses. Curr. Opin. Immunol. 5:782-787.

8. Auchincloss, H., Jr., et al. 1993. The role of "indirect" recognition in initiating rejection of skin grafts from major histocompatibility complex class II-deficient mice. Proc. Natl. Acad. Sci. USA. 90:3373-3377.

9. Bennett, S.R.M., et al. 1998. Help for cytotoxic-T-cell responses is mediated by CD40 signalling. Nature. 393:478-480.

10. Ridge, J.P., Di Rosa, F., and Matzinger, P. 1998. A conditioned dendritic cell can be a temporal bridge between a CD4+ T-helper and a T-killer cell. Nature. 393:474-478.

11. Schoenberger, S.P., Toes, R.E.M., van der Voort, E.I.H., Offringa, R., and Melief, C.J.M. 1998. T-cell help for cytotoxic T lymphocytes is mediated by CD40-CD40L interactions. Nature. 393:480-483.

12. Wecker, H., Winn, H., and Auchincloss, H.J. 1994. CD4+ T cells, without CD8+ or B lymphocytes, can reject xenogeneic skin grafts. Xenotransplantation. 1:8-16.

13. Gill, R., Wolf, L., Daniel, D., and Coulombe, M. 1994. CD4+ T cells are both necessary and sufficient for islet xenograft rejection. Transplant. 
Proc. 26:1203

14. VanBuskirk, A.M., Wakely, M.E., and Orosz, C.G. 1996. Acute rejection of cardiac allografts by noncytolytic CD4(+) T cell populations. Transplantation. 62:300-302

15. Shoskes, D.A., and Wood, K.J. 1994. Indirect presentation of MHC antigens in transplantation. Immunol. Today. 15:32-38.

16. Fangmann, J., Dalchau, R., and Fabre, J.W. 1992. Rejection of skin allografts by indirect allorecognition of donor class I major histocompatibility complex peptides. J. Exp. Med. 175:1521-1529.

17. Benham, A.M., Sawyer, G.J., and Fabre, J.W. 1995. Indirect T cell allorecognition of donor antigens contributes to the rejection of vascularized kidney allografts. Transplantation. 59:1028-1032.

18. Chen, W., et al. 1996. Mechanisms of indirect allorecognition in graft rejection. Class II MHC allopeptide-specific T cell clones transfer delayed-type hypersensitivity responses in vivo. Transplantation. 62:705-710.

19. Grusby, M.J., Johnson, R.S., Papaioannou, V.E., and Glimcher, L.H. 1991. Depletion of CD4 ${ }^{+} \mathrm{T}$ cells in major histocompatibility complex class IIdeficient mice. Science. 253:1417-1420.

20. Bosma, M., Schuler, W., and Bosma, G. 1988. The scid mouse mutant. Curr. Top. Microbiol. Immunol. 137:197-202.

21. Shelby, J., and Corry, R.J. 1982. The primarily vascularized mouse heart transplant as a model for the study of Immune Response. Heart Transplantation. 2:32-36.

22. Dialynas, D.P., et al. 1984. Characterization of the murine T cell surface molecule, designated L3T4, identified by monoclonal antibody GK 1.5: similarity of L3T4 to the human Leu 3/T4 molecule. J. Immunol. 131:2445.

23. Yin, D., and Fathman, C.G. 1995. Tissue-specific effects of anti-CD4 therapy in induction of allograft unresponsiveness in high and low responder rats. Transpl. Immunol. 3:258-264.

24. Herbert, J., and Roser, B. 1988. Strategies of monoclonal antibody therapy that induce permanent tolerance of organ transplants. Transplantation. 46:128S-134S

25. Chen, Z., Cobbold, S., Metcalfe, S., and Waldmann, H. 1992. Tolerance in the mouse to major histocompatibility complex-mismatched heart allografts, and to rat heart xenografts, using monoclonal antibodies to CD4 and CD8. Eur. J. Immunol. 22:805-810.

26. Han, W.R., Mottram, P.L., and McKenzie, I.F.C. 1993. Comparison of CD4 depleting and nondepleting monoclonal antibodies in the mouse heart allograft model. Transplant. Proc. 25:2933-2934.

27. Dalloul, A.H., Chmouzis, E., Ngo, K., and Fung-Leung, W.-P. 1996. Adoptively transferred CD4+ lymphocytes from CD8-/- mice are sufficient to mediate the rejection of MHC class II or class I disparate skin grafts. J. Immunol. 156:4114-4119.

28. Coulombe, M., Yang, H., Wolf, L.A., and Gill, R.G. 1999. Tolerance to antigen-presenting cell-depleted islet allografts is CD4 T cell dependent. J. Immunol. 162:2503-2510.

29. Bishop, D.K., et al. 1993. CD4-positive helper T lymphocytes mediate mouse cardiac allograft rejection independent of donor alloantigen specific cytotoxic T lymphocytes. Transplantation. 56:892-897.

30. Desai, N.M., et al. 1993. Islet allograft, islet xenograft, and skin allograft survival in $\mathrm{CD} 8+\mathrm{T}$ lymphocyte-deficient mice. Transplantation. 55:718-722.

31. Markmann, J.F., et al. 1992. Indefinite survival of MHC class I-deficient murine pancreatic islet allografts. Transplantation. 54:1085-1089.

32. Campos, L., et al. 1995. Survival of MHC-deficient mouse heterotopic cardiac allografts. Transplantation. 59:187-191.

33. Hao, L., Wang, Y., Gill, R.G., and Lafferty, K.J. 1987. Role of the L3T4+ T cell in allograft rejection. J. Immunol. 139:4022-4026.

34. Liu, Z., et al. 1993. Contribution of direct and indirect recognition pathways to T cell alloreactivity. J. Exp. Med. 177:1643-1650.

35. Liu, Z., et al. 1996. Indirect recognition of donor HLA-DR peptides in organ allograft rejection. J. Clin. Invest. 98:1150-1157.

36. Waaga, A.M., et al. 1998. Mechanisms of indirect allorecognition. Characterization of MHC class II allopeptide-specific T helper cell clones from animals undergoing acute allograft rejection. Transplantation. 65:876-883.

37. Chitilian, H.V., Laufer, T.M., Stenger, K., Shea, S., and Auchincloss, H., Jr. 1998. The strength of cell-mediated xenograft rejection in the mouse is due to the CD4+ indirect response. Xenotransplantation. 5:93-98.

38. Brocker, T. 1997. Survival of mature CD4 T lymphocytes is dependent on major histocompatibility complex class II-expressing dendritic cells. J. Exp. Med. 186:1223-1232.

39. Rooke, R., Waltzinger, C., Benoist, C., and Mathis, D. 1998. Targeted complementation of MHC class II deficiency by intrathymic delivery of recombinant adenoviruses. Immunity. 7:123-134.

40. Dyall, R., and Nikolic-Zugic, J. 1999. The final maturation of at least some single-positive CD4hi thymocytes does not require T cell receptormajor histocompatibility complex contact. J. Exp. Med. 190:757-764.

41. Mandelbrot, D.A., et al. 1999. Expression of B7 molecules in recipient, not donor, mice determines the survival of cardiac allografts. J. Immunol. 163:3753-3757.

42. Ito, A., Minagawa, M., Tomiyama, K., Ito, M., and Kawai, K. 1999. Cytotoxic pathways in the skin allograft rejection by CD4+ T cells. Transplantation. 68:97-100. 